\title{
A doença meningocócica na região de Sorocaba, São Paulo, Brasil, no período de 1999 a 2008
}

\author{
Meningococcal disease in the Sorocaba region, \\ São Paulo State, Brazil, 1999-2008
}

\author{
1 Instituto Adolfo Lutz, \\ Sorocaba, Brasil. \\ 2 Faculdade de Saúde \\ Pública, Universidade de São \\ Paulo, São Paulo, Brasil. \\ Correspondência \\ M. V. Leme \\ Instituto Adolfo Lutz. \\ Rua Júlio Hanser 49 \\ Sorocaba, SP 18031-000 \\ Brasil. \\ miriamvannucchi@usp.br
}

\begin{abstract}
The objective of this study was to describe the occurrence of meningococcal disease reported to the Regional Health Department in Sorocaba, São Paulo State, Brazil, from 1999 to 2008. Annual incidence of the disease was two cases per 100,000 inhabitants, with an increase from 2006 to 2008. Annual incidence rates were highest in the 0 to 4 year age bracket. Case-fatality was $21.8 \%$, higher in the 0 to 4 year age bracket (26.4\%), which also showed the highest incidence of the disease, and in the over 30-year age bracket (28\%). Diagnosis was confirmed by laboratory test in $71 \%$ of cases (culture in 45.3\%) and by clinical and epidemiological criteria in $22 \%$. Serological groups were B in $45.7 \%$, C in $47.3 \%, W 135$ in $3.7 \%$, and Y in $1.5 \%$ of the identified cases, with a predominance of $B$ from 1999 to 2003 and $C$ from 2004 to 2008. The most frequent phenotypes were B:4,7:P1.19,15 and C:23:P1.14-6. The results emphasize the need for regional surveillance of trends in the disease for early detection of outbreaks and monitoring circulating strains.
\end{abstract}

Meningococcal Meningitis; Meningococcal Infections; Lethality; Epidemiological Surveillance
Miriam Vannucchi Leme 1,2

Dirce Maria Trevisan Zanetta ${ }^{2}$

\section{Introdução}

A doença meningocócica é um importante agravo de Saúde Pública pelo seu potencial epidêmico e letalidade; além disso, deixa sequelas significativas 1. Os sorogrupos B e C são os responsáveis pela maior parte dos casos 2 .

No Brasil, a incidência média anual da doença meningocócica entre os anos de 1990 e 1999 foi de quatro casos por 100 mil habitantes, duas vezes os valores dos países desenvolvidos. A partir do ano de 2000, até 2009, a incidência no Brasil foi de 3,28 casos por 100 mil habitantes, por ano ${ }^{3}$.

No Estado de São Paulo, no ano de 1975, houve um pico (35,7 casos por 100 mil habitantes). De 1978 a 1987, a incidência permaneceu baixa, com dois casos por 100 mil habitantes por ano, mas, a partir de 1988, houve um aumento, iniciando um ciclo epidêmico que se prolongou até 2005. Entre 2000 e 2009, a incidência no Estado de São Paulo ficou em torno de 3,1 casos por 100 mil habitantes, por ano ${ }^{3}$.

Este estudo visou a descrever a incidência, bem como a letalidade total e por faixa etária, da doença meningocócica, sua distribuição por sorogrupo e os fenótipos predominantes, de 1999 a 2008, na região de Sorocaba, Departamento Regional de Saúde XVI (DRS-XVI) do Estado de São Paulo. 


\section{Metodologia}

Foram analisados os casos da doença meningocócica confirmados no DRS-XVI, de janeiro de 1999 a dezembro de 2008. Essa região compreende 48 municípios e uma população de 2,1 milhões de habitantes.

As seguintes informações foram obtidas nas fichas epidemiológicas ou no Sistema de Informação de Agravos de Notificação (SINAN): idade do paciente, data da notificação, local de residência, desfecho do caso e classificação da doença. Dos registros do Instituto Adolfo Lutz (Laboratório I, de Sorocaba), extraíram-se os dados relativos a data de entrada da amostra, exame realizado, tipo de amostra utilizada e sorogrupo identificado. No Instituto Adolfo Lutz (Central, de São Paulo), foram obtidas as informações de sorotipagem e subtipagem por métodos sorológicos. Os dados populacionais são da Fundação Sistema Estadual de Análise de Dados (Fundação SEADE). A análise dos dados foi feita para a região, para o Município de Sorocaba e para os outros 47 municípios do DRS-XVI agrupados.

Nos cálculos das incidências por faixa etária, foram considerados os grupos: 0-4 anos, 5-9 anos, 10-19 anos, 20-29 anos e 30 anos ou mais.

A doença meningocócica foi classificada de acordo com a manifestação: meningococcemia
(MCC), meningite meningocócica (MM) e meningite meningocócica com meningoccemia (MCC+MM). Foram estimadas as distribuições por manifestação.

Os critérios de confirmação diagnóstica foram classificados em laboratoriais, clínico-epidemiológico, por necropsia e atestado de óbito. Os casos diagnosticados por critério laboratorial foram classificados segundo o exame utilizado: por cultura, contraimunoeletroforese, aglutinação pelo látex e bacterioscopia e, a partir de 2007, pela técnica do RT-PCR, realizada pelo Instituto Adolfo Lutz (Central).

\section{Resultados}

Entre 1999 e 2008, ocorreram 490 casos de doença meningocócica confirmados na região do DRS-XVI, registrados pelo Grupo de Vigilância Epidemiológica-XXXI (GVE-XXXI). Os valores da incidência são mostrados na Figura 1. Em 1999 e 2000, as incidências estavam acima de três por 100 mil; a partir de 2001, ficaram em torno de dois até o final do período de estudo. Até 2005, as incidências em Sorocaba e nos outros $47 \mathrm{mu}$ nicípios foram semelhantes, porém, a partir de 2006, a cidade apresentou incidência maior que as outras, 5,5 por 100 mil habitantes no ano de 2008 , contra 0,9 , respectivamente.

Figura 1

Incidência anual da doença meningocócica no Município de Sorocaba, São Paulo, Brasil, e nos outros 47 municípios do Departamento Regional de Saúde XVI (DRS-XVI), Sorocaba, São Paulo, Brasil, no período de 1999 a 2008.

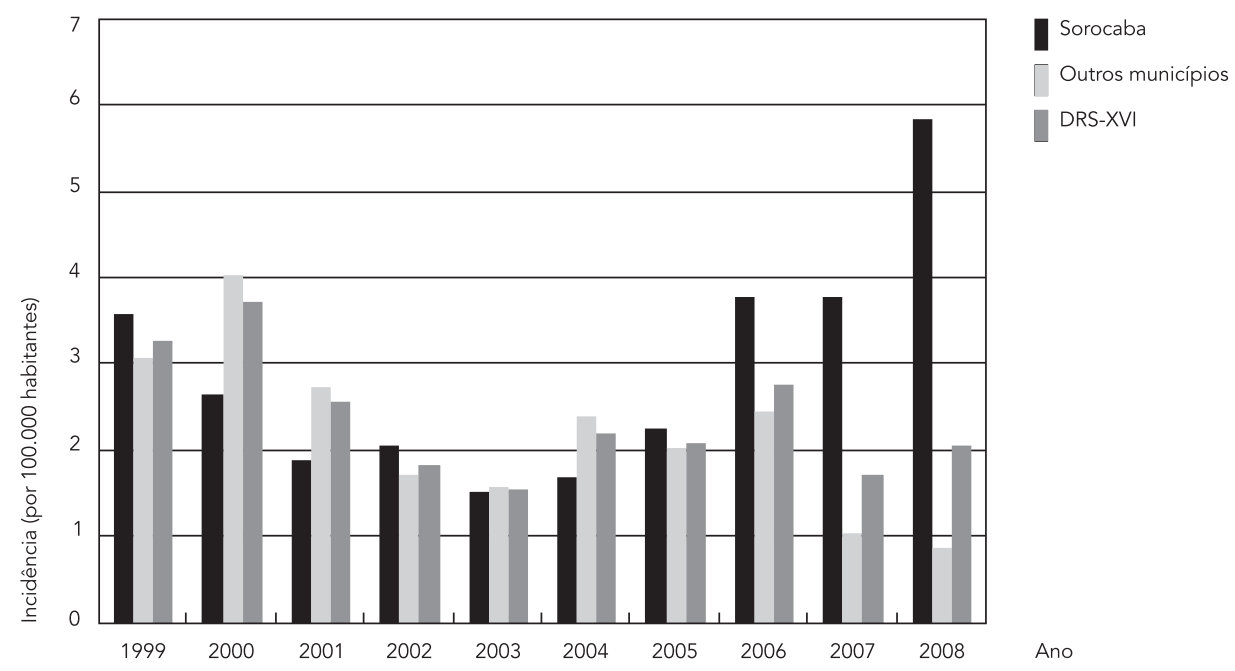


A Tabela 1 mostra as incidências por $100 \mathrm{mil}$ habitantes, por faixa etária, podendo ser observado o predomínio da ocorrência da doença em crianças de até quatro anos. A distribuição por faixa etária foi de $43,3 \%$ para $0-4$ anos; $17,3 \%$ para $5-9$ anos; $18 \%$ para $10-19$ anos; $11,2 \%$ para $20-29$ anos e $10,2 \%$ para 30 anos ou mais.

Quanto à manifestação clínica, a MM predominou, atingindo $45,1 \%$ dos casos; a forma mais grave, MCC, ocorreu em 21,4\% dos casos e MM+MCC, em 33,5\% dos casos. A distribuição das formas de manifestação clínica foi semelhante nos 47 municípios agrupados $(49,1 \%, 18,8 \%$ e $32,1 \%$, para MM, MCC e MM+MCC, respectivamente). No Município de Sorocaba, houve maior proporção de MCC (36,4\%, 27,3\% e 36,4\%, respectivamente).

A letalidade foi de $21,8 \%$, oscilando entre $8,1 \%$ e $34,8 \%$. A letalidade por faixa etária foi de $26,4 \%$ para $0-4$ anos de idade; $10,6 \%$ para $5-9$ anos; $18,2 \%$ para $10-19$ anos; $21,8 \%$ para $20-29$ anos e $28 \%$ para 30 anos ou mais.

Dos 490 casos, $71 \%$ foram diagnosticados por critérios laboratoriais, $22 \%$ de acordo com critérios clínico-epidemiológicos e $7 \%$ por resultados de necrópsias e atestados de óbito. Dos 350 casos diagnosticados laboratorialmente, cultura foi realizada em $63,4 \%$, contraimunoeletroforese ou aglutinação pelo látex, em $22 \%$, e bacterioscopia, em $14,6 \%$.

O percentual de sorogrupagem foi de $55,7 \%$ (273 de 490 doenças meningocócicas notificadas). Dentre as 273 amostras analisadas, o sorogrupo B ocorreu em 45,7\%; o C, em 47,3\%; o W135, em $3,7 \%$; o Y, em 1,5\%; e em $1,8 \%$ o sorogrupo não foi identificado. No início do período de estudo, o sorogrupo B era o mais frequente; a partir de 2004, ocorreu uma substituição do sorogrupo B pelo C (Figura 2).

Das 273 cepas cujo sorogrupo foi identificado, 142 (52\%) tiveram seu fenótipo descrito, com sorotipos e sorossubtipos identificados.

Considerando-se as 125 cepas identificadas como de sorogrupo B, 78,4\% tiveram seu fenótipo descrito, predominando o fenótipo B:4,7:P1.19,15 (46,7\%), que ocorreu em todos os anos, exceto em 2008. Os 13 fenótipos B:4,7:P1.15 descritos (13,3\%) ocorreram em 1999. Nos outros 39 casos $(39,8 \%)$, cada um dos diferentes fenótipos identificados ocorreu uma ou duas vezes. Das 129 cepas do sorogrupo C, 78 (60\%) tiveram seu fenótipo descrito, predominando o C:23:P1.14-6 $(61,5 \%, n=48)$.
Tabela 1

Incidência anual da doença meningocócica por faixa etária e total por 100 mil habitantes. Região do Departamento Regional de Saúde XVI (DRS-XVI), Sorocaba, São Paulo, Brasil, no período de 1999 a 2008.

\begin{tabular}{lllcccc}
\hline \multirow{2}{*}{ Ano } & \multicolumn{5}{c}{ Faixa etária (anos) } & Total \\
& $\mathbf{0 - 4}$ & $\mathbf{5 - 9}$ & $\mathbf{1 0 - 1 9}$ & $\mathbf{2 0 - 2 9}$ & $\mathbf{3 0}$ ou mais \\
\hline 1999 & 8,2 & 2,7 & 1,5 & 0,7 & 0,4 & 3,3 \\
2000 & 7,8 & 1,8 & 1,3 & 1,3 & 0,2 & 3,7 \\
2001 & 3,4 & 0,9 & 1,3 & 0,4 & 0,2 & 2,6 \\
2002 & 3,0 & 0,9 & 0,8 & 0,9 & 0,0 & 1,8 \\
2003 & 3,1 & 0,9 & 0,6 & 0,2 & 0,0 & 1,6 \\
2004 & 3,9 & 1,7 & 0,4 & 0,4 & 0,2 & 2,2 \\
2005 & 3,9 & 1,3 & 0,6 & 0,6 & 0,1 & 2,1 \\
2006 & 6,4 & 1,7 & 1,0 & 0,8 & 0,5 & 2,8 \\
2007 & 5,9 & 0,8 & 1,4 & 0,8 & 0,1 & 1,7 \\
$2008 *$ & 4,6 & 1,7 & 1,0 & 0,8 & 0,3 & 2,1
\end{tabular}

* Dados de 2008 não consolidados.

\section{Discussão}

A incidência no DRS-XVI foi semelhante à do Estado de São Paulo, de 4,62 casos por 100 mil habitantes no final dos anos 1990 e início nos anos 2000, declinando para 2,62 casos por $100 \mathrm{mil} \mathrm{ha-}$ bitantes na metade da década de 20004.

Em 2008, observou-se aumento, iniciado em 2006, no Município de Sorocaba. Nesse mesmo período, surtos da doença foram reportados por diversos órgãos de saúde: Porto Seguro, Bahia (2009); Búzios, Rio de Janeiro (2008); Rio Verde, Goiás (2008); Guarujá, São Paulo (2008); São José do Rio Preto, São Paulo (2008); Campinas, São Paulo (2007); São Paulo (2007) e Sete Lagoas, Minas Gerais (2007) 4,5,6.

Na região do DRS-XVI, cerca de $20 \%$ dos casos foram de MCC, forma associada à maior letalidade da doença meningocócica 4 . A letalidade média foi semelhante à relatada para Campinas nos anos de 1997 e 1998 4. Em alguns anos, o DRS-XVI apresentou valores preocupantes, como 35\% em 2004. Nesse ano, ocorreu um surto em Itapeva, com incidência de 10,4 casos por 100 mil habitantes e letalidade de $50 \%$.

As incidências por faixa etária foram maiores para crianças entre $0-4$ anos, como tem sido relatado na literatura, correspondendo a cerca de $50 \%$ dos casos. As faixas etárias de maior letalidade foram de 0-4 anos e de mais de 30 anos, com valores acima de $20 \%$, superiores à média de $17 \%$ para todo o território brasileiro 7 . Esses dados reforçam a importância da vacinação para crianças de até quatro anos. Para as populações 
Figura 2

Ocorrência de sorogrupos B e C nos casos de doença meningocócica com cepas identificados na região do Departamento Regional de Saúde XVI (DRS-XVI), Sorocaba, São Paulo, Brasil, no período de 1999 a 2008.

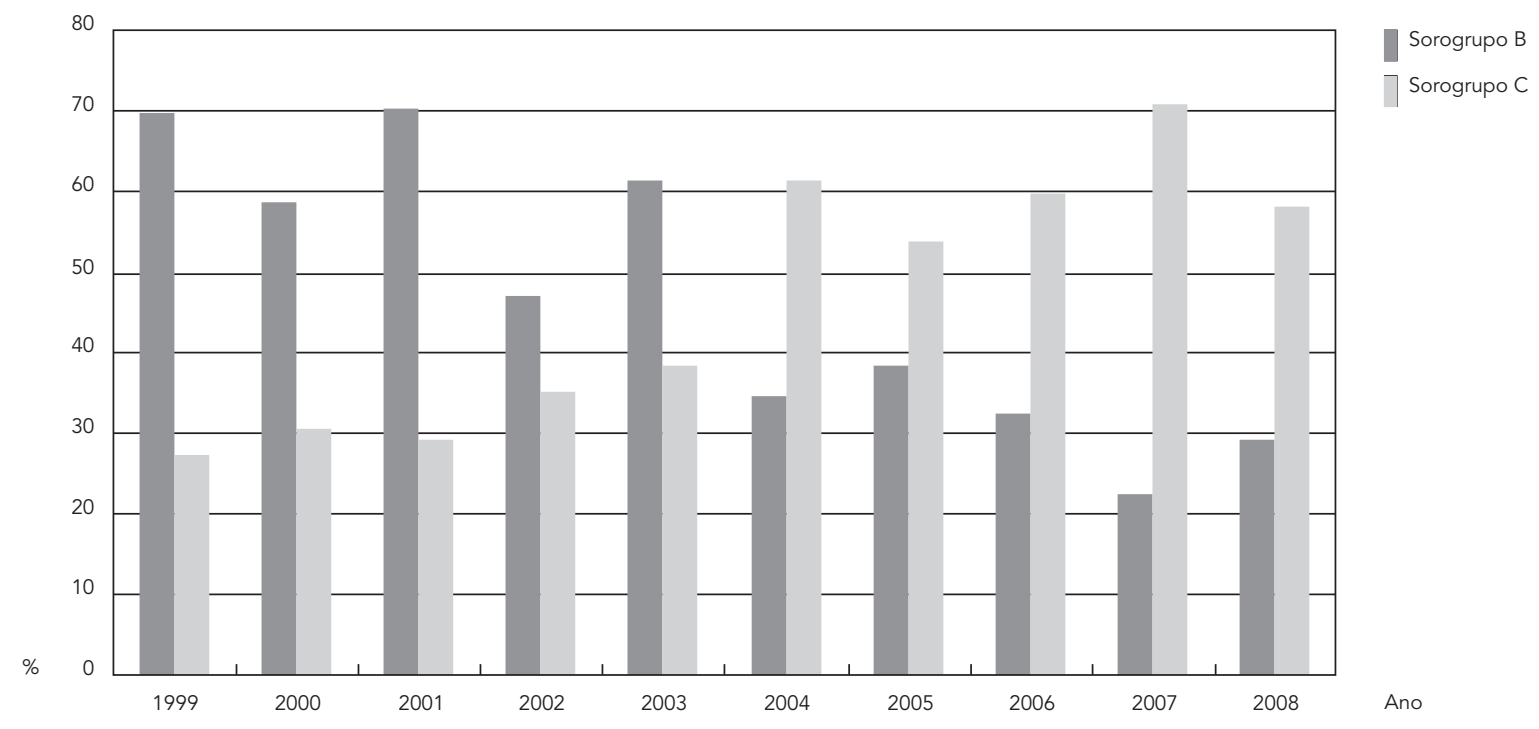

acima de trinta anos, a incidência não é muito alta, mas a letalidade o é, indicando necessidade de atenção.

A confirmação por diagnóstico laboratorial é essencial no controle da doença, indicando a qualidade do sistema de vigilância epidemiológica 4 . O percentual de casos analisados laboratorialmente no DRS-XVI foi de $72 \%$ e, em um ano crítico em termos de incidência (2008), não chegou a $60 \%$.

Entre os casos com diagnósticos confirmados laboratorialmente, $63 \%$ foram por cultura. Na região de Campinas 4, entre 1993 e 2002, 80\% dos casos tiveram confirmação laboratorial, sendo $70 \%$ por cultura. Na região de Santos, São Paulo, $32 \%$ das ocorrências confirmadas foram igualmente identificadas por cultura 8 .

Quanto aos sorogrupos isolados, houve predominância de B e C. Esses achados concordam com os dados relativos ao Estado de São Paulo e ao Brasil 8. Como em todo o país, houve, na primeira metade da década de observação, o predomínio do sorogrupo B. A partir de 2004, deu-se uma inversão, com as ocorrências do sorogrupo $\mathrm{C}$ aumentando, e as do tipo B diminuindo. Esse resultado foi compatível com o descrito para a Grande São Paulo, onde, entre 1990 e 2002, 59\% dos casos de doença meningocócica eram do sorogrupo B e 36\%, do sorogrupo C; de 2003 em diante, houve predominância de sorogrupo C, com $65 \%$ dos casos.

Nas cepas do sorogrupo B, houve predomínio de fenótipo B:4,7:P1.15, assim como na região de Santos 8. Para as cepas de sorogrupo C, o fenótipo C:23:P1.14-6 foi o mais prevalente, como na região da grande São Paulo. 


\section{Resumo}

O objetivo do estudo foi descrever a ocorrência da doença meningocócica notificada no Departamento Regional de Saúde XVI, Sorocaba, São Paulo, Brasil, no período de 1999 a 2008. Em Sorocaba, a incidência anual da doença foi de cerca de dois casos por 100 mil habitantes, com aumento entre 2006 e 2008. As incidências anuais foram maiores entre 0 a 4 anos de idade. A letalidade no período foi de 21,8\%, maior nas faixas etárias de 0 a 4 anos (26,4\%), na qual se deu a maior incidência da doença, e com idade superior a 30 anos (28\%). A confirmação diagnóstica foi laboratorial em $71 \%$ dos casos (cultura em 45,3\%) e por critérios clínico-epidemiológicos em $22 \%$. O sorogrupo B осоrreu em 45,7\%; o C, em 47,3\%; o W135, em 3,7\%; e o Y, em 1,5\% dos casos identificados, com predomínio do sorogrupo B, entre 1999 e 2003, e do C, entre 2004 e 2008. Os fenótipos B:4,7:P1.19,15 e C:23:P1.14-6 predominaram. Os resultados reforçam a necessidade de acompanhamento, de forma regional, da tendência da doença para a detecção de surtos precocemente e monitoramento de cepas circulantes.

Meningite Meningocócica; Infecções Meningocócicas; Letalidade; Vigilância Epidemiológica

\section{Referências}

1. Schwartz B, Moore PS, Broome CV. Global epidemiology of meningococcal disease. Clin Microbiol Rev 1989; 2 Suppl:S118-24.

2. Requejo HIZ. A meningite meningocócica no mundo: dois séculos de história das epidemias. São Paulo: Edições Inteligentes; 2005.

3. Coordenadoria de Controle de Doenças, Centro de Vigilância Epidemiológica Prof. Alexandre Vranjac, Governo do Estado de São Paulo. Informe técnico: vacina conjugada contra o meningococo C. São Paulo: Governo do Estado de São Paulo; 2010.

4. Donalisio MRC, Kemp B, Rocha MMM, Ramalheira RMF. Letalidade na epidemiologia da doença meningocócica: estudo na região de Campinas, SP, 1993 a 1998. Rev Saúde Pública 2000; 34:589-95.

5. Diretoria de Vigilância Epidemiológica, Superintendência de Vigilância e Proteção da Saúde. Situação epidemiológica das meningites na Bahia/2011. Boletim Epidemiológico BA 2011; Ano 5, oo. 5.

\section{Colaboradores}

M. V. Leme e D. M. T. Zanetta trabalharam na concepção, delineamento e redação final do artigo. M. V. Leme coletou e analisou os dados.

\section{Agradecimentos}

À pesquisadora A. P. S. Lemos, do Instituto Adolfo Lutz de São Paulo, por nos fornecer dados dos fenótipos das cepas analisadas no período de estudo na região DRSXVI.
6. Subsecretaria de Vigilância em Saúde de Minas Gerais. Generalidades sobre a doença e situação epidemiológica das meningites em Minas Gerais até setembro de 2009. Belo Horizonte: Secretaria de Estado da Saúde de Minas Gerais; 2009. (Boletim Informativo Meningites).

7. Centro Nacional de Epidemiologia. Evolução temporal das doenças de notificação compulsória no Brasil de 1980 a 1998. Boletim Epidemiológico 1999; Ano III, Edição Especial.

8. Arreaza ALV. Avaliação da elucidação diagnóstica das ocorrências notificadas de doença meningocócica no sistema de vigilância da Baixada Santista, entre 1998 a 2002 [Dissertação de Mestrado]. São Paulo: Faculdade de Saúde Pública, Universidade de São Paulo; 2006.

Recebido em $02 / \mathrm{Jul} / 2012$

Versão final reapresentada em 10/Set/2012 Aprovado em18/Set/2012 